\title{
A case of native valve endocarditis caused by Burkholderia cepacia without predisposing factors
}

\author{
Hyun Kyun Ki*, Sung Hea Kim, Seong Woo Han and Hae Suk Cheong
}

\begin{abstract}
Background: Infective endocarditis is rarely caused by Burkholderia cepacia. This infection is known to occur particularly in immunocompromised hosts, intravenous heroin users, and in patients with prosthetic valve replacement. Most patients with Burkholderia cepacia endocarditis usually need surgical treatment in addition to antimicrobial treatment.

Case Presentation: Here, we report the case of a patient who developed Burkholderia cepacia-induced native valve endocarditis with consequent cerebral involvement without any predisposing factors; she was successfully treated by antimicrobial agents only.
\end{abstract}

Conclusion: In this report, we also present literature review of relevant cases.

Keywords: Burkholderia cepacia Endocarditis, Native valve

\section{Background}

Burkholderia cepacia is a gram-negative bacillus. It is important nosocomial pathogen that particularly infects patients with cystic fibrosis [1] and chronic granulomatous diseases[2] and is known to be resistant to many anti-bacterial agents.

Burkholderia cepacia rarely causes endocarditis in community settings, but it is known to cause infective endocarditis particularly in intravenous heroin users, and in patients with prosthetic valve replacement [3]. However, infective endocarditis caused by Burkholderia cepacia in patients without predisposing factors is rare [4-6].

The treatment of Burkholderia cepacia endocarditis could be conservative, i.e., administration of antibacterial agents, and/or surgical modality [4-13]. According to the previous reports, most patients were prescribed trimethoprim-sulfamethoxazole and underwent valve surgery. Notwithstanding, the mortality in cases of infective endocarditis patients is not low despite the aggressive treatment of infective endocarditis [3].

Here, we report the case of a patient with Burkholderia cepacia endocarditis and cerebral involvement

\footnotetext{
* Correspondence: kihkdr@kuh.ac.kr
Department of Medicine, School of Medicine, Konkuk University, Seoul 143

* Correspondence: kihkdr@kuh.ac.kr
Department of Medicine, School of Medicine, Konkuk University, Seoul 143729 , Korea
}

(c) $2011 \mathrm{Ki}$ et al; licensee BioMed Central Ltd. This is an Open Access article distributed under the terms of the Creative Commons Attribution License (http://creativecommons.org/licenses/by/2.0), which permits unrestricted use, distribution, and reproduction in any medium, provided the original work is properly cited. successfully managed only by antimicrobial treatment. Along with this case, we also present a literature review.

\section{Case Presentation}

A 77-year-old woman was transferred to our hospital from a local hospital for loss of consciousness and disorientation. She had experienced a fall 2 weeks before admission to our hospital. Plain spine radiography had revealed a spine compression fracture. Two days earlier, she was admitted to a local hospital for relief from back pain. However, during her stay at the hospital, she developed low grade fever, aphasia, and disorientation.

She was then transferred to our hospital for further evaluation of her symptoms that were suggestive of cerebral infarction. She denied any history of smoking, alcohol consumption, or intravenous drug use. She neither had cardiovascular disease nor exhibited any of the risk factors for it. Mild aphasia and hemianopsia were noted at neurological examination. Physical examination revealed a diastolic murmur at the mitral valve area.

The clinical manifestations were suggestive of mitral stenosis and cerebral infarction associated with emboli, which was considered the preliminary diagnosis. Echocardiography revealed mitral stenosis with a mobile 10-mm sized mobile mass (Figure 1). Brain magnetic resonance imaging (MRI) revealed subacute and chronic 

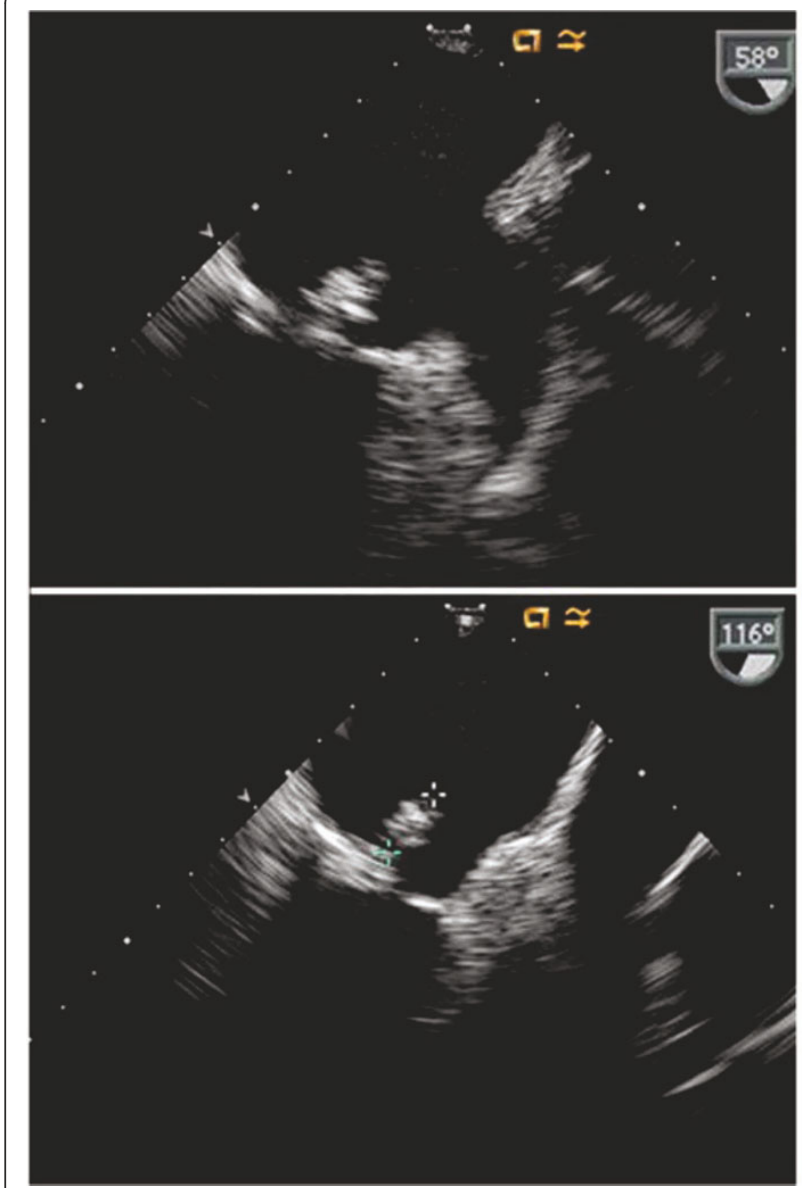

Figure 1 A 13-mm echogenic mobile mass can be seen posterior to the mitral valve leaflet at $58^{\circ}$ and $116^{\circ}$ on the transoesophageal echocardiogram. In addition, mitral stenosis (valve area $=1.7 \mathrm{~cm}^{2}$ ) with a thickened and partially mobile posterior mitral valve can be seen on the transthoracic echocardiogram.

infarction in both the cerebral hemispheres and the cerebellum (Figure 2). On day 2 of hospitalization, fever above $38^{\circ} \mathrm{C}$ was noted; therefore, blood culture test was performed. She was administered ceftriaxone $(2 \mathrm{~g} / \mathrm{d})$ and gentamicin $\left(3 \mathrm{mg} \cdot \mathrm{kg}^{-1} \cdot \mathrm{day}^{-1}\right)$ as an empirical treatment for infective endocarditis.

Despite the empirical antimicrobial treatment, intermittent low-grade fever was noted. Her blood culture was positive for Burkholderia cepacia, and antimicrobial susceptibility test yielded positive results for cefepime, ceftazidime, piperacillin, ciprofloxacin and trimethoprimsulfamethoxazole (day 7 of hospitalization). Therefore, we changed the antimicrobial treatment to ceftazidime $(6 \mathrm{~g} / \mathrm{d})$ from day 7.

Fever resolved completely from day 9, and blood culture was negative for Burkholderia cepacia. After 6 weeks of ceftazidime treatment, oral ciprofloxacin was prescribed for 2 weeks as an outpatient treatment.

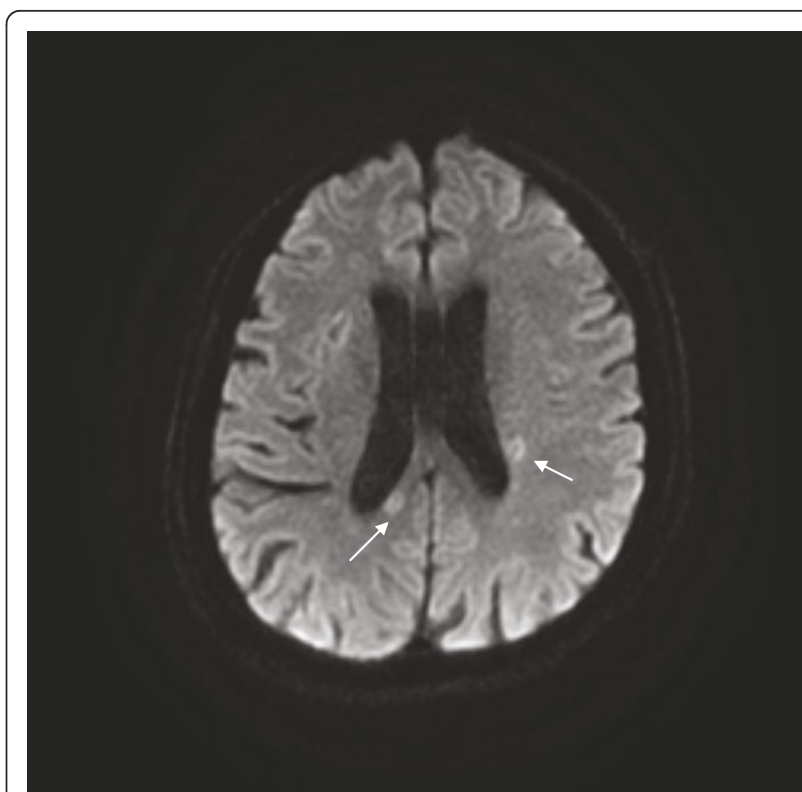

Figure 2 Subacute and chronic infarction in both cerebral hemisphere and cerebellum. High signal intensity on diffusionweighted image (arrow).

After the antimicrobial treatment course was completed, infective endocarditis resolved completely; no relapse was noted during the follow-up period for 2 years.

\section{Discussion}

Burkholderia cepacia, an opportunistic pathogen, is resistant to disinfectants and broad-spectrum antimicrobial agents. This pathogen often causes nosocomial infections in imunocompromised hosts, especially in patients with cystic fibrosis and chronic granulomatous diseases $[3,4]$. In addition, patients with cancer or chronic renal disease may also be susceptible to Burkholderia infection [14-16].

In these patients, central venous catheters are the primary source of bacteraemia [14]. Burkholderia bacteremia also noted in patients undergoing haemodialysis [15]. Burkholderia cepacia also causes infective endocarditis and skin and soft tissue pathology. This pathogen rarely causes infective endocarditis; however, there are some reports on the occurrence of this pathology in heroine addicts $[4,10-13]$ and patients with prosthetic valves and valve replacements [3-5].

In our patients, Burkholderia cepacia had infected mitral valve despite the absence of predisposing factors that would make her susceptible to the infection. This case is different from the previous reports [3-13] in the following issues. First, most of the reported cases of Burholderia cepacia endocarditis involved the prosthetic valve. In contrast, native valve endocarditis was relatively less frequent [3,4,7-9]. Burholderia cepacia-induced 
native valve endocarditis has rarely been reported. As a predisposing condition, most patients with native valve endocarditis had a history of intravenous drug abuse [3,4,7-9] and mitral valve endocarditis has mostly been reported in patients having prosthetic valves [3-5]. However, our patient did not exhibit any of the predisposing factors related to this infection described previously.

Second, trimethoprim-sulfamethoxazole is commoly used for the treatment of this infection [4-9]. However, ceftazidime was administered to our patient because of cerebral involvement and risk of trimethoprim-sulfamethoxazole allergy. Brain MRI had revealed cerebral and cerebellar infarctions in our patient. These findings suggest that the emboli had migrated into the cerebral hemispheres and induced an ischemic change of the involved regions. Therefore, an antimicrobial agent, such as ceftazidime, that could penetrate the bloodbrain barrier was required in this case.

Antimicrobial resistance of Burkholderia cepacia has posed a great challenge of treating the infection. This pathogen is intrinsically resistant to aminoglycosides and polymyxins. The antimicrobial effective against this pathogen are carbapenem, broad-spectrum beta-lactams (such as, piperacillin-tazobactam and ceftazidime), and trimethoprim-sulfamethoxazole. Therefore, because of such antimicrobial resistance, a combination of drugs and surgical treatment for valvulopathy is required $[3-7,9]$. However, we successfully treat the patient without the surgical treatment.

Third, replacement of the prosthetic or native valve has been required in most patients with infective endocarditis [3,7-9] but we did not need to perform any such surgery in our patient because of the excellent response to antimicrobial therapy. In addition, her valve function was also apparently preserved without surgery. On the bases of her valve function, life expectancy, and the morbidity involved in such surgical treatment, we decided against surgery and we were able to successfully treat the infective endocarditis by antibiotics only.

Fourth, in patients with Burkholderia cepacia endocarditis, the mitral valve is known to be less frequently involved than the tricuspid valve; mitral valve involvement has been reported in only those patients who previously had prosthetic valve replacement or valve repair surgery [3-5], and only 1 study reported aortic valve endocarditis without any predisposing factors [6].

In summary, we experienced a case of native valve endocarditis with cerebral involvement by Burkholderia cepacia without predisposing factors of Burkholderia infection, successfully managed by antimicrobial treatment only.

\section{Conclusion}

Infective endocarditis is rarely caused by Burkholderia cepacia. Recently, we encountered a patient who developed
Burkholderia cepacia endocarditis and cerebral involvement without the predisposing factors. We successfully treated the patient with only antimicrobial medication; surgical modality was not required.

\section{Consent}

Written informed consent was obtained from the patient for publication of this case report and the accompanying images. A copy of the written consent is available for review by the Editor of this journal.

\section{Acknowledgements}

We thank the patient for giving consent to publish their clinical details and the clinical photographs. Also we thank Jong Sun Ok (nurse) for helping us.

\section{Authors' contributions}

HKK drafted this manuscript. SHK and SWH managed the patient. HSC revised this manuscript. All authors read and approved the final manuscript.

\section{Competing interests}

The authors declare that they have no competing interests.

Received: 7 September 2010 Accepted: 8 May 2011

Published: 8 May 2011

\section{References}

1. Tablan OC, Chorba TL, Schidlow DV, White JW, Hardy KA, Gilligan PH, Morgan WM, Carson LA, Martone WJ, Jason JM, Jarvis WR: Pseudomonas cepacia colonization in patients with cystic fibrosis: risk factors and clinical outcome. J Pediatr 1985, 107:382-387.

2. Bottone EJ, Douglas SD, Rausen AR, Keusch GT: Association of Pseudomonas cepacia with chronic granulomatous disease. J Clin Microbiol 1975, 1:425-428.

3. Aggarwal N, Garg S, Pannu HS, Kler TS: Fatal Burkholderia cepacia early prosthetic valve endocarditis: a very rare case and a review of the literature. J Heart Valve Dis 2005, 14:271-274.

4. Noriega ER, Rubinstein E, Simberkoff MS, Rahal JJ: Subacute and acute endocarditis due to Pseudomonas cepacia in heroin addicts. Am J Med 1975, 59:29-36.

5. Speller DC: Pseudomonas cepacia endocarditis treated with cotrimoxazole and kanamycin. Br Heart J 1973, 35:47-48.

6. Welch DF, Muszynski MJ, Pai CH, Marcon MJ, Hribar MM, Gilligan PH, Matsen JM, Ahlin PA, Hilman BC, Chartrand SA: Selective and differential medium for recovery of Pseudomonas cepacia from the respiratory tracts of patients with cystic fibrosis. J Clin Microbiol 1987, 25:1730-1734.

7. Goldmann DA, Klinger JD: Pseudomonas cepacia: biology, mechanisms of virulence, epidemiology. J Pediatr 1986, 108:806-812.

8. Isles A, Maclusky I, Corey M, Gold R, Prober C, Fleming P, Levison H: Pseudomonas cepacia infection in cystic fibrosis: an emerging problem. J Pediatr 1984, 104:206-210.

9. van Pelt $C$, Verduin CM, Goessens WH, Vos MC, Tummler B, Segonds C, Reubsaet $F$, Verbrugh $H$, van Belkum A: Identification of Burkholderia spp. in the clinical microbiology laboratory: comparison of conventional and molecular methods. J Clin Microbiol 1999, 37:2158-2164.

10. Neu HC, Garvey GJ, Beach MP: Successful treatment of Pseudomonas cepacia endocarditis in a heroin addict with trimethoprimsulfamethoxazole. J Infect Dis 1973, 128(Suppl):768-770.

11. Hamilton J, Burch W, Grimmett G, Orme K, Brewer D, Frost R, Fulkerson C: Successful treatment of Pseudomonas cepacia endocarditis with trimethoprim-sulfamethoxazole. Antimicrob Agents Chemother 1973, 4:551-554.

12. Rahal JJ Jr, Simberkoff MS, Hyams PJ: Pseudomonas cepacia tricuspid endocarditis: treatment with trimethoprim, sulfonamide, and polymyxin B. J Infect Dis 1973, 128(Suppl):762-767.

13. Mandell IN, Feiner HD, Price NM, Simberkoff M: Pseudomonas cepacia endocarditis and ecthyma gangrenosum. Arch Dermatol 1977, 113:199-202. 
14. Mann T, Ben-David D, Zlotkin A, Shachar D, Keller N, Toren A, Nagler A, Smollan G, Barzilai A, Rahav G: An outbreak of Burkholderia cenocepacia bacteremia in immunocompromised oncology patients. Infection 2010, 38:187-194.

15. Martino R, Gomez L, Pericas R, Salazar R, Sola C, Sierra J, Garau J: Bacteraemia caused by non-glucose-fermenting gram-negative bacilli and Aeromonas species in patients with haematological malignancies and solid tumours. Eur J Clin Microbiol Infect Dis 2000, 19:320-323.

16. Kaitwatcharachai C, Silpapojakul K, Jitsurong S, Kalnauwakul S: An outbreak of Burkholderia cepacia bacteremia in hemodialysis patients: an epidemiologic and molecular study. Am J Kidney Dis 2000, 36:199-204.

Pre-publication history

The pre-publication history for this paper can be accessed here: http://www.biomedcentral.com/1471-2334/11/114/prepub

doi:10.1186/1471-2334-11-114

Cite this article as: Ki et al:: A case of native valve endocarditis caused by Burkholderia cepacia without predisposing factors. BMC Infectious Diseases 2011 11:114.

\section{Submit your next manuscript to BioMed Central} and take full advantage of:

- Convenient online submission

- Thorough peer review

- No space constraints or color figure charges

- Immediate publication on acceptance

- Inclusion in PubMed, CAS, Scopus and Google Scholar

- Research which is freely available for redistribution

Submit your manuscript at www.biomedcentral.com/submit 